REVISTA AMBIENTE CONTÁBIL
Universidade Federal do Rio Grande do Norte
ISSN 2176-9036
Vol. 8. n. 1, jan./jun. 2016
Sítios: http://www.periodicos.ufrn.br/ambiente
http://ccsa.ufn.br/ojs/index.php?journal=contabil
http://www.atena.org.br/revista/ojs-2.2.3-06/index.php/Ambiente

\title{
EVIDENCIAÇÃO DA MENSURAÇÃO DO VALOR JUSTO E ALUSÃo NO RELATÓRIO DO AUDITOR INDEPENDENTE
}

\section{FAIR VALUE MEASUREMENT DISCLOSURE AND ALLUSION ON AUDIT OPINION}

\section{DIVULGACIÓN DA MEDICIÓN DEL VALOR RAZONABLE Y ALLUSION EN LA OPINIÓN DE AUDITORÍA}

\author{
Autores \\ Ana Paula Belli Andruchechen \\ Doutoranda em Ciências Contábeis pela Universidade Federal de Santa Catarina - UFSC. \\ Endereço: Campus Universitário, CSE/CCN, Trindade - Florianópolis - SC - Brasil. CEP \\ 88040-510 - Fone: (47) 3644-3060 \\ E-mail: anapaula0706@hotmail.com

\section{Luiz Alberton} \\ Doutor em Engenharia de Produção pela Universidade Federal de Santa Catarina - UFSC - \\ Professor Adjunto da Universidade Federal de Santa Catarina - UFSC - Endereço: Campus \\ Universitário, CSE/CCN, Trindade - Florianópolis - SC - Brasil. CEP 88040-510 \\ Fone: (48) 3721-3825 \\ E-mail: luiz.alberton@ufsc.br
}

[Artigo baseado na Dissertação de Mestrado do Programa de Pós-Graduação em Ciências Contábeis da Universidade Federal de Santa Catarina - UFSC]

\section{RESUMO}

O objetivo deste estudo é verificar quais as evidenciações da mensuração do valor justo e as alusões nos relatórios dos auditores independentes apresentados pelas empresas de construção e engenharia listadas na BM\&FBovespa, em referência ao CPC 46. Sendo assim, teve-se como base documental as notas explicativas e os relatórios dos auditores independentes publicados por 37 empresas listadas na BM\&FBovespa. Dentre os resultados encontrados, após ser elaborado um check-list do CPC 46, destaca-se que as empresas analisadas mensuram alguns ativos, passivos e instrumentos de capital a valor justo, principalmente os ativos e passivos financeiros identificados em sua maioria como investimentos e contas a pagar. Observou-se que 20 entidades classificam os itens mensurados a valor justo em relação ao nível de hierarquia de informação, em que a maioria das classificações encontram-se no nível 2. Em relação aos relatórios dos auditores independentes, não são feitas alusões em 
Revista Ambiente Contábil - ISSN 2176-9036 - UFRN - Natal-RN. v. 8. n. 1, p. 187 - 204, jan./jun. 2016.

relação a mensuração do valor justo das empresas auditadas. Conclui-se que, na forma de evidenciação do valor justo, as empresas ainda estão em processo de adequação ao CPC 46, que necessitam de evidenciação mais específica sobre o assunto e que os relatórios dos auditores independentes não apresentam informações relevantes em relação ao valor justo.

Palavras-chave: CPC 46. Valor justo. Relatório dos auditores independentes.

\begin{abstract}
This study aims to verify which disclosures of fair value measurement and the allusions in the audit opinions provided by the construction and engineering companies listed on the $\mathrm{BM} \& \mathrm{FBovespa}$, in reference to the CPC 46. Therefore, this research has to document base the notes and the audit opinions published of 37 companies listed on the BM\&FBovespa. Among the results, after being prepared a checklist of CPC 46, it is emphasized that the companies analyzed measure certain assets, liabilities and equity instruments at fair value, mainly financial assets and liabilities identified mostly as investments and accounts payable. It was observed that 20 companies classified items measured at fair value in relation to the fair value hierarchy in that most ratings are at Level 2. In relation to audit opinions, they are not made allusions regarding of fair value measurement of the audited companies. It is concluded that, in the form of disclosure of the fair value, companies are still in the process of adaptation to CPC 46, which require more specific disclosures on the topic and that the audit opinions do not provide information relevant in relation to fair value.
\end{abstract}

Keywords: CPC 46. Fair value. Audit opinion.

\title{
RESUMEN
}

Este estudio tiene como objetivo determinar qué revelaciones de medición del valor razonable y las alusiones en las opiniones de auditoría proporcionados por las empresas de construcción e ingeniería en la BM\&FBovespa, en referencia al CPC 46. Por tanto, fue llevado como documental basado las notas y las opiniones de auditoría publicados de 37 entidades que cotizan en el mercado BM\&FBovespa. Entre los resultados, después de haber preparado una lista de verificación del CPC 46, se hizo destacar en que las empresas analizadas miden algunos activos, pasivos e instrumentos de patrimonio a valor razonable, los activos, principalmente financieros y pasivos identificados principalmente como inversiones y cuentas a pagar. Se observó que 20 entidades tienen elementos medidos a su valor razonable en relación con el nivel de jerarquía de información clasificada, en que la mayoría de clasificaciones están en el Nivel 2. En relación con las opiniones de auditoría, no se hacen alusiones relativas a la determinación del valor razonable de las empresas auditadas. Se concluye que, en forma de divulgación del valor razonable, las empresas todavía están en el proceso de adaptación al CPC 46, que requiere la divulgación más específica sobre el tema y que las opiniones de auditoría no proporcionan información pertinente en relación con su valor razonable.

Palabras clave: CPC 46. Valor razonable. Opinión de auditoría.

\section{INTRODUÇÃO}

A adoção pela contabilidade de um padrão universal pode ser justificada com a premissa de que, no atual cenário econômico mundial, a harmonização contábil é necessária para que os relatórios contábeis e econômicos sejam compreensíveis e comparáveis, oferecendo confiabilidade nas informações necessárias para a tomada de decisões (SILVA; MADEIRA; ASSIS, 2004; WEFFORT, 2005). Além disso, ao facilitar a comparabilidade das 
Revista Ambiente Contábil - ISSN 2176-9036 - UFRN - Natal-RN. v. 8. n. 1, p. 187 - 204, jan./jun. 2016.

demonstrações contábeis entre empresas situadas em diferentes países, os custos com serviços de elaboração e adequação da informação contábil tendem a diminuir (SILVA; MADEIRA; ASSIS, 2004; TAVARES et al., 2010; MAPURUNGA; MENESES; PETER, 2011; SILVA; LOPES, 2012).

Esta necessidade deu-se pela globalização dos mercados e pela abertura do mercado de capitais e consequentes investimentos estrangeiros (PRADO, 2013). Contudo, como cada país possui distintas características culturais, sociais e econômicas (SILVA; MADEIRA; ASSIS, 2004), acaba adotando métodos de publicação das demonstrações contábeis próprios, "para atender as necessidades específicas da sociedade à qual pertence" (CARMO; RIBEIRO; CARVALHO, 2011, p. 246). Neste contexto, para que os investidores tenham maior credibilidade, comparabilidade e menores riscos no mercado em que estão investindo, faz-se necessária a diminuição das divergências das informações geradas entre os países (MAPURUNGA; MENESES; PETER, 2011; SILVA; LOPES, 2012).

A importância de uma linguagem contábil unificada, para atender a necessidade dos seus usuários, pressionou órgãos internacionais em prol do desenvolvimento e da divulgação de normas e procedimentos que suprissem esta demanda (PONTE et al., 2012). Estas circunstâncias levaram ao surgimento e fortalecimento de órgãos para desenvolver padrões de contabilidade uniformes e de alta qualidade (HENDRIKSEN; VAN BREDA, 2007).

No Brasil, a aprovação da Lei $\mathrm{n}^{\circ}$ 11.638/07 corresponde uma das principais etapas do processo de convergência das normas brasileiras para as normas internacionais de contabilidade (LORENCINI; COSTA, 2012), ficando sob a responsabilidade do Comitê de Pronunciamentos Contábeis (CPC) a tradução e adaptação das normas emitidas pelo IASB. Entretanto, antes de 2007 já existiam empresas que evidenciaram as suas demonstrações contábeis em conformidade com as normas internacionais. Mas, somente em 2010 houve a obrigação de publicar as demonstrações de acordo com a nova normatização.

Dentre as alterações trazidas pela Lei 11.638/07, destaca-se a mensuração do valor justo (embasada pelo CPC 46) em função do foco deste artigo, que pode ser definido como "o preço que seria recebido pela venda de um ativo ou que seria pago pela transferência de um passivo em uma transação ordenada entre participantes do mercado na data de mensuração" (CPC 46, 2012, p. 3). Para Zyla (2009) esta mensuração traz alterações no valor de apresentação de ativos e passivos fazendo com que os investidores requeiram maiores informações para a tomada de decisões com base em relatórios financeiros. No entanto, algumas mensurações podem ser inconstantes o que justifica a necessidade de revisão dos procedimentos de avaliação do valor justo divulgado (MACKENZIE et al., 2013).

No Brasil, o IFRS 13 foi traduzido e utilizado na elaboração do CPC 46 (CPC, 2012). O objetivo deste pronunciamento técnico é definir valor justo, estabelecendo, em um único pronunciamento técnico, uma estrutura para a sua mensuração e evidenciação (CPC, 2012). No entanto, com a convergência das normas internacionais de contabilidade no Brasil, para Mendes e Freire (2014) a adoção do valor justo no processo para a mensuração de ativos e passivos fez surgir a possibilidade de as empresas gerenciarem os seus resultados e manipularem as informações contábeis. Como exemplo disso, Barros et al. (2012) observam que as notas explicativas de empresas brasileiras geralmente são superficiais e apresentam informações insuficientes para a compreensão da situação dos ativos, comprometendo o entendimento dos stakeholders.

Assim, para transmitir maior credibilidade e veracidade às informações contidas nos registros contábeis, uma entidade pode utilizar os serviços da auditoria (FRANCO; MARRA, 2001). Para Dutra (2011), os usuários externos utilizam-se da opinião dos auditores para tomar suas decisões. Espera-se que os serviços de auditoria garantam credibilidade, uma vez que a falta de qualidade dos relatórios pode comprometer a confiança por parte dos usuários nas demonstrações contábeis (SANTOS; GRATERON, 2003). 
Para delimitar a abrangência da pesquisa, este artigo tem como foco as notas explicativas e os relatórios dos auditores independentes divulgados pelas companhias listadas no subsetor de construção e engenharia da Bolsa de Valores, Mercadorias \& Futuros de São Paulo (BM\&FBovespa). A escolha por este conjunto de empresas deve-se à representatividade socioeconômica do setor de construção e engenharia no cenário brasileiro.

De acordo com o Anuário Estatístico da Secretaria do Desenvolvimento da Produção (2012), somente no ano de 2011 o setor de construção e engenharia possuía mais de 2,5 milhões de empregos gerados no mercado formal e uma taxa média de crescimento do PIB (Produto Interno Bruto) anual de 3,6\%. Contudo, os dados de junho de 2014 da Confederação Nacional da Indústria (CNI) apontam uma diminuição no número de empregados e deterioração da situação financeira deste setor (CNI, 2014).

Diante deste contexto, verificando-se a obrigatoriedade das empresas listadas na BM\&FBovespa em divulgar suas informações contábeis em conformidade com as normas vigentes, ao mesmo tempo em que existem relatos de baixa qualidade da divulgação dessas informações, este estudo se propõe a responder à seguinte questão problema: Quais as evidenciações da mensuração do valor justo e as alusões nos relatórios dos auditores independentes publicados pelas empresas de construção e engenharia listadas na BM\&FBovespa, em referência ao CPC 46?

Com a finalidade de responder ao problema formulado, o objetivo geral desta pesquisa é verificar quais as evidenciações da mensuração do valor justo e alusões nos relatórios dos auditores independentes publicados pelas empresas de construção e engenharia listadas na BM\&FBovespa, em referência ao CPC 46. Para auxiliar no cumprir o objetivo geral, são apresentados alguns objetivos específicos: i) verificar se as empresas analisadas seguem o disposto no CPC 46; ii) investigar como as empresas analisadas evidenciam as informações sobre o valor justo; iii) averiguar nas notas explicativas os ativos e passivos que mais tiveram menção a ajustes; iv) analisar o conteúdo dos relatórios dos auditores independentes em referência ao valor justo.

Este estudo justifica-se, primeiramente, pela sua relevância científica nos aspectos referentes à avaliação do valor justo pelas companhias do subsetor de construção e engenharia listadas na BM\&FBovespa, o qual tem representatividade socioeconômica com empregabilidade de milhões de pessoas no Brasil e atualmente enfrenta problemas financeiros (ABRASCA, 2014; CNI, 2014). Especificamente, é realizada uma investigação sobre a evidenciação da mensuração do valor justo pelas companhias e sua confrontação com as informações contidas nos relatórios dos auditores independentes. Por sua vez, Christensen, Glover e Wood (2013) sugerem que os relatórios financeiros e os padrões de auditoria sejam alterados para gerar mais transparência e clareza no nível de incerteza das estimativas contábeis, nas quais se inclui o valor justo. Outro fator importante refere-se aos estudos acadêmicos na perspectiva do IFRS 13 e do CPC 46, que ainda são incipientes.

\section{REFERENCIAL TEÓRICO}

\subsection{NORMAS INTERNACIONAIS DE CONTABILIDADE}

A procura pela uniformização contábil no Reino Unido e nos Estados Unidos começou no final do século XIX em resposta à competição acirrada das indústrias, que não tinham um padrão contábil (MOST, 1982). A comparação dos relatórios contábeis emitidos em países diferentes traz benefícios aos usuários destas informações para interpretá-los com maior coerência. Para isso, o processo de convergência contábil objetiva a integração das práticas contábeis entre os países de acordo com a necessidade da informação contábil de seus usuários (OLIVEIRA, 2010). Nesse sentido, Beck et al. (2012) referem-se o processo de 
Revista Ambiente Contábil - ISSN 2176-9036 - UFRN - Natal-RN. v. 8. n. 1, p. 187 - 204, jan./jun. 2016.

harmonização das demonstrações contábeis como um auxílio aos gestores, investidores e analistas financeiros para utilizarem dados transparentes e homogêneos ao comparar os dados e resultados das entidades analisadas.

Com a globalização, a queda das barreiras comerciais entre os países e, mais recentemente, a reação à crise econômica financeira global (MIRZA; HOLT, 2011) ocorreu a necessidade em ter um padrão internacional de contabilidade. Para Mirza e Holt (2011), a adoção dos IFRS pelas entidades é bem vista pelos investidores, credores, analistas financeiros e outros usuários dos relatórios financeiros emitidos, pois requer maior qualidade, transparência e comparabilidade das informações a serem analisadas.

Existem alguns benefícios para as entidades ao adotar o IFRS como base para emissão de seus relatórios. Fabiano (2012) destaca que os principais benefícios para esta convergência são a redução da assimetria da informação, um mercado mais eficiente e o aumento do grau de comparabilidade das informações, prevalecendo assim a essência sobre a forma.

Com o objetivo de suprir a necessidade da harmonização das normas internacionais de contabilidade, o IASB emitiu as Internacional Accouting Statements (IAS) e a partir de 2003 as denominou como IFRS (PRADO, 2013). Elas representam um conjunto de normas baseadas em princípios e não em regras (MIRZA; HOLT, 2011). As normas internacionais de contabilidade são utilizadas por aproximadamente 130 países que requereram ou permitiram o uso das IFRSs desde 2001 (IASB, 2014), cujo objetivo é unificar a linguagem contábil nas demonstrações contábeis das empresas. O IFRS tem como objetivo promover a integração mundial do mercado de capitais, tratando em uma só linguagem os seus relatórios financeiros (ZYLA, 2009).

Para Prado (2013), a exigência de instituições internacionais, como o Banco Mundial e a Organização Mundial do Comércio, foi um fator de favorecimento para a adoção das IFRS pelas empresas europeias, as quais deveriam adotar as IFRSs em suas demonstrações contábeis para utilizar os serviços financeiros destas instituições. Dentre estes países que adotaram o IFRS, destaca-se o Brasil que o adotou progressivamente desde 2008.

\subsection{A CONVERGÊNCIA CONTÁBIL NO BRASIL}

A convergência para as normas internacionais de contabilidade no Brasil, segundo Pessotti (2012), ocorreu no Brasil em duas etapas. A primeira etapa, apontada como norma de transição, iniciou um processo de convergência parcial das demonstrações contábeis do exercício social de 2008, sendo oficializada com a aprovação da Lei ${ }^{\circ} 11.638 / 07$, com a Medida Provisória $n^{\circ} 449 / 08$ (posteriormente transformada na Lei $n^{\circ} 11.941 / 09$ ) e com a implementação dos CPCs 01 ao 14, em que se destaca o CPC 13, que contém as orientações necessárias para a adoção inicial dos padrões internacionais. Já a segunda etapa, denominada de adoção plena, foi caracterizada com a emissão de vários outros CPCs, destacando-se o CPC 37 que orienta a adoção inicial das normas internacionais de contabilidade.

A criação do Comitê de Pronunciamentos Contábeis (CPC) foi um importante passo dado no Brasil, ficando sob sua responsabilidade a tradução e adaptação das normas emitidas pelo IASB. De acordo com Iudícibus et al. (2010), seis entidades não governamentais, sendo elas o Conselho Federal de Contabilidade (CFC), a Associação dos Analistas e Profissionais de Investimento do Mercado de Capitais (APIMEC NACIONAL), com a Associação Brasileira das Companhias Abertas (ABRASCA), a BM\&FBovespa, com a Fundação Instituto de Pesquisas Contábeis, Atuariais e Financeiras (FIPECAFI) e o Instituto dos Auditores Independentes do Brasil (IBRACON), emitiram a Resolução $\mathrm{n}^{\circ} 1.055 / 05$, criando esse Comitê que é suportado pelo Conselho Federal de Contabilidade, mas possui independência em suas deliberações (Pronunciamentos Técnicos, Interpretações e Orientações). Desde a emissão do primeiro pronunciamento contábil em 2007, o CPC já 
Revista Ambiente Contábil - ISSN 2176-9036 - UFRN - Natal-RN. v. 8. n. 1, p. 187 - 204, jan./jun. 2016.

emitiu 48 pronunciamentos técnicos. Atualmente, 45 CPCs estão em vigor com a finalidade de manter o padrão contábil.

De acordo com a Instrução da Comissão de Valores Mobiliários (CVM) n. ${ }^{\circ}$ 457/07, a adoção das normas internacionais de contabilidade, de acordo com os pronunciamentos emitidos pelo IASB, se tornou obrigatória no Brasil para as companhias abertas a partir do exercício social de 2010 e do exercício anterior para fins comparativos (CVM, 2007). Para que as demonstrações contábeis sejam publicadas no Brasil, devem ser seguidas as orientações específicas de entidades regulamentadoras, dentre elas o CPC. Iudícibus et al. (2010) presumem que a aplicação dos Pronunciamentos, Orientações e Interpretações do CPC garante às demonstrações contábeis a adequação necessária para que os relatórios sejam interpretados, comparados e analisados por usuários interessados, mesmo que de outros países.

Há tempos que a preparação das demonstrações contábeis de acordo com o IFRS é debatida por seus conhecedores em relação à sua relevância, transparência e utilidade para a tomada de decisão de acordo com o IFRS (MACKENZIE et al., 2013). Para esses autores, as mensurações de ativos e passivos incluem custos históricos e as aproximações aos valores econômicos correntes, dentre eles o valor justo.

\subsection{VALOR JUSTO}

Ao trazer o valor justo para a contabilidade, os relatórios financeiros para a tomada de decisões ficam mais próximos da realidade das entidades. Zyla (2009) defende que o valor justo representa a posição financeira da entidade e fornece maior relevância para os usuários destas informações financeiras e patrimoniais.

Most (1982, p. 233) define o valor justo como "um preço em que uma propriedade pode mudar de 'mãos' entre um comprador e um vendedor interessado, informado e independente". Iudícibus e Marion (2001) caracterizam o valor justo como a importância pelo qual um ativo poderia ser transacionado entre um comprador disposto e conhecedor do assunto e um vendedor também disposto e conhecedor do assunto em uma transação sem favorecimento. Em complemento a este conceito, Hendriksen e Van Breda (2007) mencionam que é o valor que os investidores estão dispostos a receber com um retorno justo aplicado. Já para a KPMG (2011), o valor justo pode ser definido como "o preço que seria recebido na venda de um ativo ou pago para transferir um passivo em uma transação ordenada entre os participantes de um mercado na data de mensuração, ou seja, um preço de saída" que se aplicaria em uma transação entre os participantes do mercado (mercado ativo ou estimado utilizando uma técnica de avaliação).

Em se tratando de normatizações, o CPC 46 (2012, p. 3) define o valor justo como "o preço que seria recebido pela venda de um ativo ou que seria pago pela transferência de um passivo em uma transação ordenada entre participantes do mercado na data de mensuração". $\mathrm{O}$ valor justo ainda pode ser definido como um preço de saída baseado no mercado e em uma transação não forçada, sem favorecimentos (IFRS 13, 2011).

Ao ser tratada no Brasil, a mensuração do valor justo teve seu auge com a aprovação do CPC 46 pela Deliberação CVM n ${ }^{\circ}$ 699/12 e pela Resolução CFC nº 1428/13, no dia 07 de dezembro de 2012, em que este pronunciamento técnico se relaciona com a norma internacional IFRS 13 (CPC, 2012). O objetivo deste pronunciamento técnico é definir valor justo, estabelecer em um único pronunciamento técnico uma estrutura para a sua mensuração e estabelecer as divulgações sobre mensurações (CPC, 2012).

A obrigatoriedade da aplicação do CPC 46 dá-se prospectivamente para as demonstrações contábeis com os períodos anuais com início em $1^{\circ}$ de janeiro de 2013 , sendo permitida a aplicação anterior a este período, contanto que este fato seja divulgado em nota 
Revista Ambiente Contábil - ISSN 2176-9036 - UFRN - Natal-RN. v. 8. n. 1, p. 187 - 204, jan./jun. 2016.

explicativa. Para Barros et al. (2012, p. 54) o IFRS 13 "aumenta a transparência da avaliação do valor justo, exigindo divulgações detalhadas sobre valores justos derivados usando modelos".

O valor justo é uma mudança fundamental na mensuração de ativos e passivos para propósitos de relatórios financeiros, que fez com que os investidores requeressem informações relevantes para suas tomadas de decisões (ZYLA, 2009). Mackenzie et al. (2013) apontam que os dados atuais sobre o valor justo são mais fáceis de serem obtidos, porém algumas destas medidas são inconstantes, refletindo a turbulência da economia no mercado de crédito. Para Mendes e Freire (2014. p. 55), o IFRS 13 permite a "liberdade de os gestores a escolherem o nível de avaliação pelo valor justo a ser aplicado em ativos e passivos". Esta volatilidade justifica a necessidade em revisar os mecanismos pelos quais os valores justos são avaliados e mensurados.

Para a KPMG (2011), a mensuração do valor justo aplica-se aos ativos, passivos e instrumentos de capital próprio da entidade que, de acordo com outros IFRSs, são exigidos ou permitidos a serem mensurados pelo valor justo. De acordo com o CPC 46 (2012), para mensurar o valor justo, a entidade deve determinar os seguintes quesitos:

a) o ativo, passivo ou instrumentos de capital próprio específico que estão sendo mensurados;

b) para um ativo não financeiro, o maior e melhor uso do ativo e se o ativo é usado em combinação com outros ativos ou em uma base independente;

c) o mercado em que uma transação normal teria lugar para o ativo ou passivo; e

d) as técnicas de avaliação apropriadas a serem utilizadas para mensurar o valor justo, as quais devem maximizar o uso de dados observáveis relevantes, minimizar os dados não observáveis e serem consistentes com as técnicas que um participante do mercado utilizaria para precificar o ativo ou passivo.

O valor justo de um ativo ou passivo deve ter a sua mensuração baseada no mercado principal a que estejam dispostos a serem negociados (na ausência de um mercado principal, deverão ser baseados em um mercado mais vantajoso para a negociação), usando as premissas que os participantes do mercado utilizariam para precificar este ativo ou passivo, e não em uma medida específica da entidade. Porém, este mercado poderá ser diferente entre as entidades, dependendo da atividade que a mesma exerce (CPC, 2012).

Ao mensurar o valor justo nos passivos ou nos instrumentos de capital próprio, a entidade deve pressupor a transferência deste para um participante no mercado em que a) o passivo permaneceria em aberto e este participante fosse obrigado a cumprir a obrigação; e b) o instrumento de capital permanecesse em aberto e o participante do mercado assumisse os direitos e responsabilidades associadas a este instrumento. Dentre estes mercados, destacamse aqueles em que as informações podem ser observáveis para alguns ativos e passivos, tais como, os mercados de câmbio, mercados de corretagem e mercados não intermediados. Para estas mensurações, a entidade deve sempre maximizar as informações observáveis e minimizar os dados não observáveis, bem como considerar os riscos de não cumprimento destes itens (CPC, 2012).

Contudo, Amaral (2014) salienta que existem discussões sobre o valor justo, em que alguns autores não concordam com a sua mensuração. Uma das principais críticas ao valor justo é a dificuldade elencada ao fazer a mensuração, tornando os dados menos confiáveis quando não há um mercado ativo (BOLÍVAR; GALERA, 2012).

O reconhecimento inicial de um ativo ou passivo feito pela entidade é o preço de transação dos itens em questão, os quais nem sempre são iguais ao valor justo destes ativos e passivos. De acordo com o CPC 46 (2012), isto pode acontecer em quatro ocasiões específicas: a) transação entre partes relacionadas; b) operação em que o vendedor é obrigado a aceitar um valor menor que o justo (por exemplo, estar em dificuldades financeiras); c) a unidade de contabilização da transação é diferente da unidade de contabilização do ativo ou 
Revista Ambiente Contábil - ISSN 2176-9036 - UFRN - Natal-RN. v. 8. n. 1, p. 187 - 204, jan./jun. 2016.

passivo (por exemplo, uma combinação de negócios); d) o mercado de transação é diferente do mercado principal (ou mais vantajoso) de negociação. No entanto, o valor de mercado nem sempre está disponível para o ativo ou passivo a ser avaliado. Por este motivo, "resolveu-se ampliar o conceito, aplicando certos modelos matemáticos e valores calculados estatisticamente (...) e ainda há a alternativa de usar o conceito de fluxo de caixa descontado" (MARTINS, 2008).

Em referência ao valor justo, as evidenciações das entidades devem fornecer informações que contribuam com a análise dos usuários das demonstrações contábeis (CPC, 2012). Ao identificar os ativos e passivos mensurados a valor justo nas demonstrações contábeis após o reconhecimento inicial, os usuários precisam saber as técnicas de avaliação e as informações utilizadas pelas entidades para fazer as mensurações. Além disso, o CPC 46 (2012, p. 18) orienta que a entidade deve divulgar:

(a) para ativos e passivos que sejam mensurados ao valor justo de forma recorrente ou não recorrente na demonstração da posição financeira após o reconhecimento inicial, as técnicas de avaliação e informações utilizadas para desenvolver essas mensurações.

(b) para mensurações do valor justo recorrentes que utilizem dados não observáveis significativos (Nível 3), o efeito das mensurações sobre os lucros e perdas ou outros resultados abrangentes para o período.

Para tanto, a entidade deve considerar o nível de detalhe necessário para satisfazer os requisitos de divulgação, a quantidade de ênfase e agregação (ou desagregação) a ser empreendida nos requisitos e as informações adicionais que os usuários das demonstrações necessitariam para avaliar as informações quantitativas divulgadas (CPC, 2012). O valor justo de um ativo, passivo ou instrumento de capital deverá ser classificado entre os Níveis de hierarquia 1, 2 ou 3, dependendo da informação constante para mensurar este valor justo. No Quadro 1 demonstram-se as especificações de cada Nível.

\section{Quadro 1 - Níveis Hierárquicos de Informação}

\begin{tabular}{|c|c|l|}
\hline $\mathbf{N}^{\mathbf{0}}$ & Descrição & Características \\
\hline 1 & Informações Confiáveis & $\begin{array}{l}\text { Valores cotados em mercados ativos para ativos e passivos idênticos que } \\
\text { a entidade possa acessar na data da mensuração. Esta cotação fornece a } \\
\text { evidência mais confiável do valor justo e deve ser utilizada sem ajustes } \\
\text { para a mensuração. }\end{array}$ \\
\hline 2 & $\begin{array}{l}\text { Informações Sujeitas à } \\
\text { Ajustes }\end{array}$ & $\begin{array}{l}\text { Valores incluídos no Nível 1, porém cotados direta ou indiretamente em } \\
\text { mercados ativos referente aos ativos e passivos similares (ou mercados } \\
\text { não ativos para ativos e passivos idênticos). Tais cotações podem ser } \\
\text { utilizadas com pequenos ajustes no momento da mensuração. }\end{array}$ \\
\hline 3 & $\begin{array}{l}\text { As informações contêm variáveis não observáveis para o ativo ou } \\
\text { passivo. Estas variáveis devem ser utilizadas para mensurar o valor justo } \\
\text { na medida em que dados observáveis relevantes não estiverem } \\
\text { disponíveis em situações em que não há ou há pouca atividade de } \\
\text { mercado para o ativo ou passivo a ser mensurado. }\end{array}$ \\
\hline
\end{tabular}

Fonte: Adaptado de CPC 46 (2012)

Tendo como base o Quadro 1, Mendes e Freire (2014) salientam que não existe discricionariedade no Nível 1 de hierarquia de informação em razão de os preços serem cotados, mas os Níveis 2 e 3 são suscetíveis a ajustes nos preços o que permite ser discricionários. Para fazer esta classificação dos ativos e passivos por níveis de informação, a entidade deve determinar a classe de cada um deles, com base na natureza, características e riscos. A quantidade de classes pode ser maior na mensuração do valor justo de Nível 3, pois o grau de incerteza e subjetividade é maior. Assim, quanto maior a proporção de ativos e passivos classificados no Nível 1, menores são as chances de manipulação de resultados (MENDES; FREIRE, 2014). 
Revista Ambiente Contábil - ISSN 2176-9036 - UFRN - Natal-RN. v. 8. n. 1, p. 187 - 204, jan./jun. 2016.

No entanto, a entidade precisa fornecer informações suficientes que permitam a reconciliação dos valores apresentados no Balanço Patrimonial (IFRS 13, 2011). Para Laghi et al. (2012) os princípios de hierarquia permitem maior compreensão dos dados contábeis, mas ainda há a problemas com subjetividade na estimativa do valor justo.

De acordo com o CPC 46 (2012), para cada classe de ativos e passivos mensurados a valor justo a entidade deverá divulgar as seguintes informações após o reconhecimento inicial:

a) as mensurações do valor justo no final do período em análise e as suas respectivas razões;

b) os níveis da hierarquia de valor justo;

c) os valores, as razões e as políticas adotadas para as transferências efetuadas entre Nível 1 e Nível 2 da hierarquia;

d) descrições das técnicas de avaliação e os dados utilizados na mensuração do valor justo para as mensurações categorizadas no Nível 2 e Nível 3 da hierarquia;

e) para as mensurações categorizadas no Nível 3: i) as informaçõoes quantitativas sobre as contribuições significativas não observáveis utilizadas na mensuração; ii) uma reconciliação dos saldos iniciais e finais; iii) divulgação separada das alterações durante o período sobre: ganhos ou perdas totais reconhecidos no resultado do período ou nos resultados abrangentes, operações de compras, vendas, emissões e liquidações; iv) os montantes de quaisquer transferências feitas no Nível 3 da hierarquia e as suas razões e políticas; v) uma descrição dos processos de avaliação utilizados pela entidade caso as mensurações de ativos não financeiros sejam diferentes do seu maior e melhor uso, divulgar esse fato juntamente com o motivo deste ativo estar sendo usado de tal maneira.

Todos os fatos acima devem ser apresentados em divulgações quantitativas em um formato tabular, a menos que outro formato seja mais adequado para tais evidenciações (IFRS 13, 2011). No entanto, Skoda e Bilka (2012) afirmam que a mensuração a valor justo é suscetível a manipulação de preços que podem fazer com que as empresas repassem informações enganosas a seus usuários. Assim, Jacques, Rasia e Ott (2012) enfatizam que a evidenciação dos aspectos subjetivos pode demonstrar uma diferenciação da empresa analisada em relação aos seus concorrentes. Neste sentido, para que o usuário da informação contábil tenha segurança de que as demonstrações contábeis estão elaboradas e evidenciadas adequadamente e obedecendo as normas contábeis vigentes, as empresas utilizam-se dos serviços de auditoria (FRANCO; MARRA, 2001).

\subsection{AUDITORIA DO VALOR JUSTO NAS DEMONSTRAÇÕES CONTÁBEIS}

A fraude contábil é uma das preocupações para a economia mundial, sendo constatada em empresas que até então eram consideradas incorruptíveis, o que tem relação direta com a fragilidade da legislação contábil e fiscal (ASSING; AVILA; ALBERTON, 2010). Para estes mesmos autores, as técnicas de auditoria auxiliam a detectar as distorções e melhorar os controles patrimoniais das empresas.

Martin, Rich e Wilks (2006) destacam a necessidade de o auditor entender como a mensuração do valor justo é preparada e as etapas de auditoria, bem como os procedimentos que são necessários para verificar e atestar a mensuração elaborada pelas empresas auditadas. Isto se justifica com o pouco (ou nenhum) treinamento que os auditores possuem em avaliação, necessitando de ajuda de especialistas para compor a auditoria, caso contrário, poderá levar a um relatório de auditoria baseado em julgamentos distorcidos (MARTIN; RICH; WILKS, 2006). 
Revista Ambiente Contábil - ISSN 2176-9036 - UFRN - Natal-RN. v. 8. n. 1, p. 187 - 204, jan./jun. 2016.

Power (2010) prescreve que o auditor fornece a confiabilidade de que os valores representados nas demonstrações são reais, suportados por metodologias de avaliação econômica institucionalmente credíveis. Salienta-se ainda que, o valor justo pode ser subjetivo, principalmente, quando são classificados nos Níveis hierárquicos de informação 2 e 3 (POWER, 2010).

Em seu estudo sobre o valor justo aplicado na empresa Enron, Benston (2006) acredita que a utilização da mensuração do valor justo dos itens contábeis foi consideravelmente responsável para a falência da empresa, levando em consideração que a maioria dos itens estavam elencados no Nível 3 de hierarquia de informação. No que se refere à auditoria independente, os auditores da Arthur Andersen aprovaram os instrumentos contábeis utilizados pelos contadores. Os contadores relataram os fluxos de caixa das operações ao invés dos financiamentos, encobrindo os exageros e as perdas de valor justo projetados pelos gestores para compensação futura baseada em valores de mercado (BENSTON, 2006).

Em um estudo mais recente, Christensen, Glover e Wood (2013, p. 36) destacam que "a incerteza global inerente nas demonstrações financeiras tem aumentado nas últimas décadas, mas os relatórios relacionados ao nível exigido de auditoria de assurance mudaram muito pouco". Tal subjetividade inclui a mensuração do valor justo que, muitas vezes, pode ser maior que a relevância típica de auditoria adotada. Mesmo com o aumento de complexidade das demonstrações contábeis, "os auditores são obrigados a fornecer uma garantia razoável, definido em normas de auditoria como 'alta garantia' que as demonstrações financeiras tomadas em conjunto estão adequadamente apresentadas, em todos os aspectos relevantes" (CHRISTENSEN; GLOVER; WOOD, 2013, p. 36).

Contudo, vale destacar que estas contribuições não representam afirmações sobre o tema de pesquisa deste trabalho. Apenas demonstram a direção que as empresas podem seguir em relação ao valor justo e a sua possível alusão nos relatórios dos auditores independentes, que podem auxiliar nas análises necessárias para responder o problema em questão.

\section{METODOLOGIA}

Ao se tratar de enquadramento metodológico, esta pesquisa é classificada com o objetivo descritivo. No entanto, esta pesquisa é recente em seu campo estudado, trazendo como temática a evidenciação do valor justo em empresas brasileiras pertencentes à amostra, bem como a alusão nos relatórios dos auditores independentes. Assim, faz-se a descrição da realidade do objeto de estudo. Para oferecer a sustentação teórica, o procedimento de pesquisa dá-se por meio de pesquisa documental. A técnica de pesquisa documental é realizada analisando-se dados secundários que envolvem as demonstrações contábeis divulgadas nas páginas eletrônicas de organismos reguladores das empresas estudadas. Quanto à abordagem do problema, esta pesquisa é classificada como qualitativa ao ser uma forma de compreender a natureza do fenômeno social que é a aplicação do valor justo e a alusão nos relatórios dos auditores independentes.

Para a escolha da população e amostra desta pesquisa, foram selecionadas as empresas listadas na BM\&FBovespa no subsetor de Construção e Engenharia do setor de Construção e Transporte. A escolha deste subsetor justifica-se pela importância socioeconômica. A seleção da amostra teve como base as empresas que estavam listadas no dia 02 de junho de 2014 no site da BM\&FBovespa, conforme consulta em seu próprio site, descartando a possibilidade de haver mais empresas que poderiam constar nesta listagem após esta data, assim foram encontradas 39 empresas neste subsetor. Como a análise é composta somente dos dados contábeis de 2013 destas empresas, foram excluídas a SERGEN e a CONST BETER, tendo em vista que as últimas demonstrações contábeis encontradas no site da BM\&FBovespa eram de 2010 e 2012, respectivamente, inviabilizando a análise dos dados para esta pesquisa. 
Revista Ambiente Contábil - ISSN 2176-9036 - UFRN - Natal-RN. v. 8. n. 1, p. 187 - 204, jan./jun. 2016.

Para atingir os objetivos propostos, esta pesquisa se desenvolveu em duas etapas: a coleta de informações sobre o valor justo nas notas explicativas das empresas e a coleta de informações sobre o valor justo que foi evidenciado nos relatórios dos auditores independentes. Ao elaborar o constructo da coleta de informações sobre o valor justo nas notas explicativas, foi elaborado um check-list do CPC 46 para servir como base na organização das informações obtidas.

A construção do check-list limitou-se ao CPC 46, sendo dividido em blocos de acordo com a sua estrutura: (i) introdução, (ii) escopo, (iii) hierarquia e (iv) evidenciação. Para preencher o check-list, todos os itens foram classificados de acordo com a aplicação do CPC 46 nas empresas analisadas, podendo ser "sim", "não", "n.a" (não se aplica), "n.m.n” (não menciona nada) e, caso necessário, um campo para preenchimento de observações específicas.

Inicialmente foi realizado o download dos arquivos das informações financeiras padronizadas do ano de 2013 das empresas da amostra no site da BM\&FBovespa. Por meio do programa EmpresasNet ${ }^{\circledR}$ esses arquivos foram importados para o programa com o intuito de trabalhar com as informações financeiras.Com os dados importados no programa, foi possível classificar as empresas de acordo com o seu segmento, ano das demonstrações contábeis, situação do emissor na CVM, localização de cidade, estado e país e se as demonstrações foram consolidadas. Na sequência, no mesmo programa, foram coletados os dados referentes a auditoria independente.

Após esta coleta de dados, foram obtidas as notas explicativas em formato PDF para verificar se as empresas mencionaram em algum momento o termo "IFRS 13" ou "CPC 46", bem como puderam ser verificadas a mensuração, ou não, do valor justo e quais itens foram mensurados. Todas as informações referentes ao CPC 46 foram coletadas das notas explicativas das empresas analisadas. Foi realizada a leitura de todas as notas explicativas para então coletar os dados. Estes dados foram tabulados em planilha eletrônica do Microsoft@ Excel@ e separadas para cada empresa. Após o seu preenchimento, os dados de todas as empresas foram agrupados em uma única planilha para cada bloco do check-list.

$\mathrm{Na}$ última etapa ocorreu a confrontação das informações encontradas no relatório dos auditores independentes com o valor justo. Com os relatórios coletados do mesmo programa, foi realizada a sua leitura e verificada a alusão que os auditores atribuíram ao valor justo.

\section{RESULTADOS E ANÁLISES}

Toda a análise da pesquisa referente à mensuração do valor justo foi realizada de acordo com as divulgações contidas em notas explicativas de cada empresa. Ao verificar a utilização da mensuração do valor justo, constatou-se que 36 empresas mensuram seus ativos, passivos e/ou instrumentos de capital com base na norma. Para a única empresa que não utiliza a mensuração do valor justo (Lix da Cunha), conforme descrito no CPC 46, nada é tratado a respeito da divulgação de informações sobre esta não utilização.

Nas notas explicativas divulgadas pelas empresas foi verificado se, em algum momento, é divulgada alguma informação sobre o IFRS 13 ou CPC 46. Destaca-se que 14 empresas mencionam o IFRS 13 e 12 empresas mencionam o CPC 46.

A não divulgação dos termos "IFRS 13" ou "CPC 46" constatada em 20 empresas, não faz com que elas estejam descumprindo a norma contábil, porém esta não divulgação pode dificultar o entendimento da informação contábil. As empresas que não mencionaram as normas não foram descartadas das análises, pois não é possível afirmar que elas não as aplicam para elaborar as demonstrações contábeis. Contudo, existem alguns itens que são de 
Revista Ambiente Contábil - ISSN 2176-9036 - UFRN - Natal-RN. v. 8. n. 1, p. 187 - 204, jan./jun. 2016.

divulgação obrigatória pelas empresas, dentre eles encontram-se as informações sobre a mensuração a valor justo dos ativos, passivos e instrumentos de capital.

A princípio, nenhuma empresa teve aplicação desta norma em períodos anteriores a 2013, o que pode ser constatado com a busca de informações nas notas explicativas de 2011 e 2012 de algumas empresas, pois esta informação não consta em suas notas explicativas de 2013. Porém, 5 empresas não fizeram nenhuma evidenciação quanto a este fato. Caso tivesse aplicação desta norma anterior à 2013, esta ocorrência deveria ser divulgada.

Ainda foram relacionadas a aplicação do CPC 46 aos ativos, passivos e instrumentos de capital. Inicialmente, foram feitas buscas nas notas explicativas sobre os itens mensurados a valor justo. Nesta busca, 35 empresas aplicaram o valor justo em seus ativos, 33 nos passivos e 4 nos instrumentos de capital, conforme demonstrado na Tabela 1.

Tabela 1 - Aplicação dos itens de introdução do CPC 46

\begin{tabular}{|c|c|c|c|c|}
\hline Item analisado & Sim & Não & N.A. & N.M.N. \\
\hline Teve aplicação deste CPC anterior à 2013? & - & 32 & - & 5 \\
\hline Se sim, foi divulgado este fato? & - & - & 32 & 5 \\
\hline O valor justo é aplicado em ativos? & 35 & 2 & - & - \\
\hline O valor justo é aplicado em passivos? & 33 & 4 & - & - \\
\hline O valor justo é aplicado em instrumentos de capital? & 4 & 30 & - & 3 \\
\hline
\end{tabular}

Fonte: Dados da pesquisa (2014)

Como pode ser observado na Tabela 1, a aplicação do valor justo em ativos, que teve maior destaque foi em instrumentos financeiros (tanto ativos como passivos), em que 32 empresas evidenciaram de alguma forma que eles estão mensurados a valor justo.

Das 5 empresas que não divulgaram a mensuração do valor justo em instrumentos financeiros, 3 divulgaram a mensuração a valor justo somente para: contratos de arrendamento mercantil; salários, férias e encargos sociais; imobilizados e intangíveis. Tais itens também são abordados em algumas outras empresas que mensuram a valor justo os instrumentos financeiros, mas não com tanta frequência. Ainda existe uma empresa (CSU) que divulgou que os valores contidos no balanço patrimonial se aproximam do valor justo e, conforme já mencionado, a empresa Lix da Cunha não faz mensurações com base no valor justo.

Contudo, em referência à parte introdutória do CPC 46, pode-se notar que as empresas analisadas não aplicaram esta norma nas demonstrações contábeis anteriores. Para 2013, os itens que mais foram evidenciados encontram-se nos ativos e passivos, destacando-se os financeiros, como o caixa e equivalentes de caixa, contas a pagar e a receber, investimentos e empréstimos.

Um dos requisitos do CPC 46 é a classificação dos níveis de informação a serem adotados para a mensuração do valor justo. Estes níveis são classificados em hierarquias de acordo com o acesso à informação. Dentre as 37 empresas analisadas, 36 apresentam ativos, passivos ou instrumentos de capital mensurados ao valor justo. Mas apenas 20 empresas divulgaram a classificação em níveis hierárquicos: Altus, BR Brokers, Brookfield, Direcional, Eternit, Even, Gafisa, Helbor, JHSF Part., João Fortes, Lopes Brasil, Mendes Jr, Mills, MRV, PDG Realt, RodobensImob., Sondotécnica, TGLT, Valid e Viver.

Nenhuma empresa classifica os instrumentos de capital em níveis hierárquicos, somente classificam seus ativos e passivos. Esta informação contradiz os dados encontrados na Tabela 1em que, no item de Introdução, as empresas Brookfield, Gafisa, Lopes Brasil e Mills informaram aplicar o valor justo em instrumentos de capital. Cabe destacar que estas 4 empresas afirmaram classificar as informações do valor justo em níveis hierárquicos.

A mesma contradição pode ser constatada na mensuração do valor justo dos ativos e passivos. Enquanto que na Tabela 1 a mensuração do valor justo foi em 35 empresas para os 
Revista Ambiente Contábil - ISSN 2176-9036 - UFRN - Natal-RN. v. 8. n. 1, p. 187 - 204, jan./jun. 2016.

ativos e 33 empresas os mensuram em passivos, apenas 19 e 4 empresas, respectivamente, classificam em níveis de informação entre ativos e passivos. A não classificação em níveis hierárquicos de informação pode comprometer o cumprimento do CPC 46.

A concentração da classificação em níveis hierárquicos de informação está nos ativos classificados em Nível 1. Existe divergência ao comparar este dado com o estudo de Mendes e Freire (2014) sobre as instituições financeiras, em que há predominância em avaliar os ativos nos níveis mais subjetivos (Níveis 2 e 3). Para as informações de Nível 1, os ativos classificados abrangem somente instrumentos financeiros.

O Nível 2 de informação foi a classificação que mais teve ativos e passivos divulgados pelas empresas, mas mesmo assim há contradição entre a Tabela 1 estes dados. Assim como no Nível 1, somente ativos e passivos tiveram suas classificações neste nível.

Em relação ao Nível 3 de hierarquia, apenas as empresas BR Brokers, Lopes Brasil e PDG Realt tiveram ativos e passivos classificados. Os ativos classificados são os instrumentos financeiros com opções de venda (localizados em 2 empresas) e as propriedades para investimento. As mesmas empresas que fizeram a classificação dos instrumentos financeiros com opções de venda classificaram as opções de compra de instrumentos financeiros e passivos financeiros designados ao valor justo por meio de resultado, respectivamente.

As empresas apresentaram resultados diferentes em alguns quesitos de evidenciação. O primeiro item que o CPC 46 trata sobre a evidenciação é quanto a divulgação das técnicas de avaliação utilizadas para desenvolver as mensurações a valor justo de ativos e passivos, podendo ser observado que 32 empresas evidenciam os seus ativos e apenas 17 empresas evidenciaram as técnicas utilizadas em seus passivos. Este dado difere dos resultados encontrados no estudo de Mendes e Freire (2014) que demonstram apenas 5,5\% das empresas classificadas no estudo divulgaram informações referente a avaliação de ativos e passivos a valor justo.

Caso a empresa efetue a transferência entre os níveis de hierarquia, deverá evidenciar em notas explicativas os valores, razões e políticas utilizadas para fazer esta transferência. Dentre as 20 empresas que classificaram as mensurações de valor justo em níveis hierárquicos de informação, nenhuma aplicou a transferência de níveis.

O parágrafo 99 do CPC 46 (2012) é claro ao mencionar que "a entidade deve apresentar as divulgações quantitativas exigidas por este Pronunciamento em um formato tabular, salvo se outro formato for mais apropriado". Porém, apenas 13 empresas fazem em um formato tabular: BR Brokers, Brookfield, Contax, Eternit, JHSF Part, Lopes Brasil, Mills, PDG Realt, RodobensImob, Sondotécnica, Tecnosolo, TGLT e Valid; a maioria delas o faz para representar a localização da conta contábil e o seu nível de hierarquia. As empresas que não fazem a apresentação desta forma, evidenciam apenas informações descritivas no decorrer das notas explicativas, deixando a forma tabular para outras divulgações que não sejam referentes ao valor justo.

Após verificar as evidenciações da mensuração do valor justo feitas pelas empresas analisadas em coerência com o CPC 46, esta etapa da pesquisa demonstra a alusão dos relatórios dos auditores independentes em referência ao CPC 46. Para tanto, foram lidos todos os relatórios e constatou-se que nenhum auditor independente mencionou a norma contábil analisada, nem como IFRS 13 e nem como CPC 46. No entanto, 21 auditores mencionaram em seu relatório o termo "valor justo", havendo assim a necessidade de analisar estes relatórios com a finalidade de descobrir a alusão dada à evidenciação deste item.

Em seu conteúdo no relatório do auditor independente, 20 empresas tiveram a mesma alusão no parágrafo de ênfase, mencionando que as demonstrações contábeis individuais foram elaboradas de acordo com as práticas contábeis adotadas no Brasil. Mas essas práticas diferem das IFRS aplicáveis às demonstrações contábeis separadas, somente no que se refere à avaliação dos investimentos em controladas pelo método de equivalência patrimonial, uma 
Revista Ambiente Contábil - ISSN 2176-9036 - UFRN - Natal-RN. v. 8. n. 1, p. 187 - 204, jan./jun. 2016.

vez que para fins de IFRS seria custo ou valor justo. Para todos os auditores, esta ênfase não faz com que a opinião seja ressalvada em função deste assunto.

Ainda houve um auditor da TAG Auditoria e Consultoria Empresarial que emitiu um relatório com ressalva em referência às demonstrações contábeis da empresa Tecnosolo pelo motivo de: "o acervo patrimonial vertido para a empresa controlada foi valorado com atribuição de valor justo, tendo como base o laudo de avaliação citado na nota explicativa 23". Esta nota explicativa trata dos ajustes de avaliação patrimonial.

\section{CONCLUSÃO}

$\mathrm{O}$ atendimento às normas internacionais de contabilidade pelas companhias brasileiras passou a ser obrigatório a partir de 2010. Dentre as normas listadas, o IFRS 13, que foi traduzido e utilizado na elaboração do CPC 46, refere-se à mensuração e evidenciação das demonstrações contábeis a valor juto. Este pronunciamento permite a subjetividade em algumas condições específicas e que devem ser divulgadas de forma clara e objetiva pela empresa.

O objetivo geral deste trabalho foi de verificar quais as evidenciações da mensuração do valor justo e as alusões nos relatórios dos auditores independentes apresentados pelas empresas de construção e engenharia listadas na BM\&FBovespa, em referência ao IFRS 13. Assim, foram analisadas as empresas do subsetor de construção e engenharia que estavam listadas no site da BM\&FBovespa no dia 02 de junho de 2014. Para a coleta das informações e análise dos dados, foi desenvolvido um check-list com base no CPC 46. Desta forma, foi possível tabular os dados e compreender como as empresas deste setor estão evidenciando as informações sobre valor justo e quais as alusões que os auditores fazem em seus relatórios sobre este tema.

Das 37 empresas analisadas, apenas uma não aplica o valor justo em suas contas e 20 empresas não citam o IFRS 13 e nem o CPC 46 em suas notas explicativas. A aplicação do CPC 46 anterior a 2013 não aconteceu em nenhuma empresa, conforme pesquisa realizada nas notas explicativas de anos anteriores.

Em referência aos itens mensurados a valor justo, destacam-se os ativos e passivos financeiros, em que, respectivamente, 35 e 34 empresas o fizeram. Apenas 20 empresas fazem a classificação em níveis hierárquicos e, a maioria delas, possui a classificação de ativos no Nível 2 de hierarquia. $O$ fato de as empresas não fazerem esta aplicação, pode estar associado com a dificuldade em saber como fazer esta classificação, pois os dados podem ser obtidos de diversas formas para suportar a mensuração, mesmo estando em grupo de ativos e passivos. Embora a maioria das empresas não tenha classificado o nível de hierarquia, as técnicas de avaliação e insumos utilizados são divulgadas em 32 empresas, fazendo com que, ao menos, a base para fazer a mensuração seja identificada.

A divulgação das informações sobre o valor justo é incentivada pelo CPC 46 em ser de forma tabular. Ao todo, 13 empresas divulgam em forma tabular e 22 empresas divulgam os valores durante as outras explicações características de cada item específico, geralmente incluído no texto da nota explicativa. Cabe destacar que uma empresa não mensura os seus ativos e passivos a valor justo e outra relata que os valores informados se aproximam dos valores justos.

Quanto a alusão dos relatórios dos auditores independentes, não há referência à norma analisada, apenas abordam no parágrafo de ênfase a questão de que as demonstrações contábeis individuais foram elaboradas de acordo com as práticas contábeis adotadas no Brasil, mas essas práticas diferem das IFRS aplicáveis às demonstrações contábeis separadas, somente no que se refere à avaliação dos investimentos em controladas pelo método de 
Revista Ambiente Contábil - ISSN 2176-9036 - UFRN - Natal-RN. v. 8. n. 1, p. 187 - 204, jan./jun. 2016.

equivalência patrimonial, uma vez que para fins de IFRS seria custo ou valor justo. Ressaltase neste tópico que os relatórios dos auditores independentes são semelhantes e não tratam de questões específicas, fazendo com que tenham o mesmo padrão, inclusive na forma escrita do relatório.

Portanto, pode-se afirmar que as empresas não estão em total acordo com as evidenciações exigidas pelo CPC 46 e que os relatórios dos auditores independentes não fazem alusões específicas quanto a mensuração do valor justo. Esta norma é recente e, assim como o processo de convergência aos padrões internacionais de contabilidade no Brasil, chega-se à conclusão de que as empresas ainda estão em processo de desenvolvimento da mensuração ao valor justo.

Para futuros trabalhos, recomenda-se replicar esta pesquisa em outros setores e subsetores da economia, bem como realizar comparações para conhecer quais as empresas e setores que estão em conformidade com os pronunciamentos contábeis. Do mesmo modo, é possível que este estudo seja replicado para analisar setores da economia de outros países que também adotam as IFRSs como base para seus pronunciamentos contábeis.

\section{REFERÊNCIAS}

ABRASCA. Anuário estatístico das companhias abertas 2013/2014. Disponível em: <http://www.abrasca.org.br/anuario/2012/> Acesso em: 06/09/2014.

AMARAL, N. A. L. A utilização do valor justo para mensuração da receita econômica: o que o mercado tem a dizer sobre o valor do curso de Ciências Contábeis da UFSC?. 2014. 156 f. Dissertação (Mestrado em Contabilidade) - Universidade Federal de Santa Catarina, Florianópolis (SC), 2014.

ASSING, I.; AVILA, R. V.; ALBERTON, L. Atendimento às Normas na Reavaliação de Ativos Imobilizados e nos Pareceres Emitidos por Auditoria Independente. Revista de Informação Contábil, v. 4, n. 1, p. 01 - 21, 2010.

BARROS, C. C.; SOUZA, F. J. V.; ARAÚJO, A. O.; SILVA, J. D. G.; SILVA, M. C. O Impacto do Valor Justo na Mensuração dos Ativos Biológicos nas Empresas Listadas na BM\&FBovespa. Revista de Contabilidade do Mestrado em Ciências Contábeis da UERJ, V. 17, n. 3, p. 41-59, 2012.

BECK, F.; MOURA, G. D.; KLANN, R. C.; BEZERRA, F.A. Principais alterações internas em uma empresa de capital aberto: um estudo do impacto da convergência contábil sob a ótica contingencial. In: VI Congresso ANPCONT, v.6., 2012. Anais... São Paulo, ANPCONT, 2012.

BENSTON; G. J. Fair-value accounting: A cautionary tale from Enron. Journal of Accounting and Public Policy, v. 25, n. 4, p. 465-484, 2006.

BOLÍVAR, M. P. R.; GALERA, A. N. The Role of Fair Value Accounting in Promoting Government Accountability. Abacus, v. 48, n. 3, p. 348-386, 2012.

CARMO, C. H. S.; RIBEIRO, A. M.; CARVALHO, L. N. G. Convergência de fato ou de direito? A influência do sistema jurídico na aceitação das normas internacionais para 
Revista Ambiente Contábil - ISSN 2176-9036 - UFRN - Natal-RN. v. 8. n. 1, p. 187 - 204, jan./jun. 2016.

pequenas e médias empresas. Revista de Contabilidade \& Finanças, v. 22, n. 57, p. 242 $262,2011$.

CHRISTENSEN, B. E.; GLOVER, S. M.; WOOD, David A. Extreme Estimation Uncertainty and Audit Assurance. Current Issues in Auditing, v. 7, n. 1, p. P36-P42, 2013.

CNI. Sondagem Indústria da Construção. Disponível em: $<$ http://arquivos.portaldaindustria.com.br/app/conteudo_24/2014/08/22/54/SondagemIndustri adaConstruoJunho2014.pdf> Acesso em: 05/09/2014

COMISSÃO VALORES MOBILIARIOS (CVM). Instrução CVM n 457. Brasília: CVM, 2007.

CPC. Disponível em: <http://www.cpc.org.br/pronunciamentosIndex.php>. Acesso em: 07/03/2014.

FABIANO, D. O nível de comparabilidade contábil dos países do BRIC. 2012. 127 f. Dissertação (Mestrado em Administração) - Faculdade de Gestão e Negócios, Universidade Federal de Uberlândia, Uberlândia (MG), 2012.

FRANCO, H.; MARRA, E. Auditoria Contábil. 4 ed. São Paulo: Atlas, 2001.

HENDRIKSEN, E. S.; VAN BREDA, M. F. Teoria da Contabilidade. $5^{\text {a }}$ Ed. São Paulo: Atlas, 2007.

INTERNATIONAL ACCOUTING REPORTING STANDARDS BOARDS. International Financial Reporting Standard 13: Fair Value Measurement. 2011. Disponível em: <http://eifrs.ifrs.org/eifrs/bnstandards/en/2012/ifrs13.pdf>. Acesso em: 30/04/2014.

Quem somos e o que fazemos. Disponível em: <http://www.ifrs.org/Theorganisation/Documents/WhoWeAre_Portuguese_JAN_2014.pdf>. Acesso em: 29/08/2014.

INTERNATIONAL FINANCIAL REPORTING STANDARDS. Standards and Interpretations. Disponível em: <http://www.ifrs.org/IFRSs/Pages/IFRS.aspx>. Acesso em: $31 / 08 / 2014$.

IUDÍCIBUS, S.; MARION, J. C. O Dicionário de Termos de Contabilidade. São Paulo: Atlas, 2001.

IUDÍCIBUS, S.; MARTINS, E.; GELBCKE, E. R.; SANTOS, A. Manual de Contabilidade Societária. 1. ed. São Paulo: Atlas, 2010.

JACQUES, F. V. S.; RASIA, K. A.; OTT, E. A evidenciação do ativo intangível em notas explicativas por empresas de capital aberto integrantes na Bovespa. Revista Espacios, v. 33, n. 3 , p. $13-28,2012$.

KPMG. Orientação unificada para mensuração e divulgação do valor justo para IFRS. IFRS em destaque. São Paulo, dez. 2011. Disponível em: <http://www.kpmg.com/BR/PT/Estudos_Analises/artigosepublicacoes/Documents/IFRS/IFR S_em_destaque_IFRS_13.pdf $>$. Acesso em: 02/03/2014. 
Revista Ambiente Contábil - ISSN 2176-9036 - UFRN - Natal-RN. v. 8. n. 1, p. 187 - 204, jan./jun. 2016.

LAGHI, E.; PUCCI, S.; TUTINO, M.; MARCANTONIO, M. Fair value hierarchy in financial instrument disclosure. Is there transparency for investors? Evidence from the banking industry. Journal of Governance and Regulation, v. 1, Issue 4, 2012.

LORENCINI, F. D.; COSTA, F.M. Escolhas contábeis no Brasil: identificação das características das companhias que optaram pela manutenção versus baixa dos saldos do ativo diferido. Revista de Contabilidade \& Finanças, v. 23, n. 58, p.52-64, Jan-Abr, 2012.

MACKENZIE, B.; COETSEE, D.; NJIKIZANA, T.; COLYVAS, B.; HANEKOM, B. IFRS 12 interpretação e aplicação. Porto Alegre: Bookman, 2013.

MAPURUNGA, P.V.R.; MENESES, A.F.; PETER, M.G.A. O processo de convergência das normas internacionais de contabilidade: uma realidade nos setores privado e público brasileiros. Revista Controle, v. 09, n. 1, 87-107, Jan-Jun, 2011.

MARTIN, R., D,; RICH, J., S.; WILKS, T., J. Auditing Fair Value Measurements: A Synthesis of Relevant Research. Accounting Horizons, v.20, n. 3, p. 287-283, 2006.

MENDES, C.J.F.; FREIRE, F.S.A governança corporativa e manipulação de informação contábil: mensuração a valor justo nos bancos comerciais. Revista Contemporânea de Contabilidade, v. 11, n. 23, 53-76, Mai-Ago, 2014.

MIRZA, A. A.; HOLT, G. J. Pratical Implementation Guide and Workbook for IFRS. 3. ed. New Jersey: John Wiley \& Sons, 2011.

MOST, K. S. Accounting theory.2. ed. Columbus, Ohio: Grid, 1982.

OLIVEIRA, V. A. Adoção inicial das normas contábeis internacionais por empresas brasileiras. 2010. 154 f. Dissertação (Mestrado em Administração) - Faculdade de Gestão e Negócios, Universidade Federal de Uberlândia, Uberlândia (MG), 2010.

PESSOTTI, T. J. Impacto da convergência às normas internacionais de contabilidade sobre a acurácia dos analistas do mercado de capitais brasileiro. 2012. $70 \mathrm{f}$. Dissertação (Mestrado em Ciências Contábeis) - Fundação Ensino Capixaba de Pesquisa em Contabilidade, Economia e Finanças, Vitória, 2012.

PONTE, V. M. R.; DE LUCA, M. M. M.; OLIVEIRA, M. C.; DE AQUINO, L. D. P; CAVALCANTE, D. S. Análise do grau de cumprimento das práticas de divulgação definidas pelo pronunciamento técnico CPC 13 no âmbito das companhias abertas. Revista de Educação e Pesquisa em Contabilidade (REPeC), v. 6, n. 1, 2012.

POWER, M. Fair value accounting, financial economics and the transformation of reliability. Accounting and Business Research, v.40, n. 3, p. 197-210, 2010.

PRADO, T. A. R. Os impactos da primeira adoção das normas IFRS nas demonstrações contábeis das companhias abertas brasileiras. 2013. 123 f. Dissertação (Mestrado em Administração) - Faculdade de Gestão e Negócios, Universidade Federal de Uberlândia, Uberlândia (MG), 2013. 
Revista Ambiente Contábil - ISSN 2176-9036 - UFRN - Natal-RN. v. 8. n. 1, p. 187 - 204, jan./jun. 2016.

SANTOS, A. D.; GRATERON, I.R.G. Contabilidade criativa e responsabilidade dos auditores. Revista Contabilidade \& Finanças, v. 14, n. 32, p. 07-22, 2003.

SECRETARIA DO DESENVOLVIMENTO DA PRODUÇÃO: Anuário Estatístico 2012. In: Ministério do Desenvolvimento, Indústria e Comércio Exterior, Secretaria do Desenvolvimento da Produção. Brasília: SDP, 2012. Disponível em: <http://http://www.desenvolvimento.gov.br>. Acesso em: 29 abr. 2014.

SILVA, C.B.A.; MADEIRA, G.J.; ASSIS, J.L.F. Harmonização de normas contábeis: um estudo sobre as divergências entre normas contábeis internacionais e seus reflexos na contabilidade brasileira. Revista Contemporânea de Contabilidade, v.1, n.1, 115-139, 2004.

SILVA, R. L. M.; LOPES, A. B. Demonstrações contábeis no Brasil após adoção do CPC 13: reação do mercado de ações e consequências econômicas. In: $12^{\circ}$ Congresso USP de Controladoria e Contabilidade, v 12, 2012 - FEA-USP. Anais... São Paulo, FEA/USP, 2012.

SKODA, M.; BILKA, P. Fair value financial statements - advantage and disadvantage. Studia Universitatis "Vasile Goldiş" Arad. Economics Series, v.22, Issue 2, 2012.

TAVARES, M. T. N; RIBEIRO FILHO, F.; LOPES, J. E. G; VASCONCELOS, M. T. C; PEDERNEIRAS, M. M. M. Reconhecimento, mensuração e evidenciação contábil: um estudo sobre o nível de conformidade das empresas listadas na Bovespa com o CPC 01 redução ao valor recuperável de ativos. Sociedade, Contabilidade e Gestão (UFRJ), v. 05, p. 01-17, 2010 .

WEFFORT, E. F. J. O Brasil e a harmonização contábil internacional: influências dos sistemas jurídico e educacional, da cultura e do mercado. São Paulo: Atlas, 2005.

ZYLA. M. L. Fair Value Measurements: Practical Guidance and Implementation. John Wiley \& Sons, 2009. 